\title{
Usage of ProSeal Laryngeal Mask Airway with Low Cuff Pressure
}

The Editor,

Sir,

In the present article, we want to share our experience with usage of ProSeal laryngeal mask airway (LMA) with $45 \mathrm{~cm} \mathrm{H} \mathrm{H}_{2} \mathrm{O}$ cuff pressure in twelve adult patients undergoing inguinal hernia surgery under general anaesthesia. Laryngeal mask airway and developed models has been used as an alternative to endotracheal tube for many years in anaesthesia practice. Several studies indicated that LMA devices, including LMA ProSeal, caused lower haemodynamic responses during intubation and lower postoperative side effects compared to endotracheal tubes (1). Many studies indicate that reduction and monitorization of LMA intracuff pressure may lower the incidence of postoperative pharyngolaryngeal complications (2).

We used Proseal LMA (Number 5) with lower cuff pressure $\left(45 \mathrm{~cm} \mathrm{H}_{2} \mathrm{O}\right)$ than recommended $\left(60 \mathrm{~cm} \mathrm{H}_{2} \mathrm{O}\right)$ for twelve male adult patients. Patient characteristics are specified in the Table.

Table: Patient characteristics

\begin{tabular}{ll}
\hline Age $($ years $)$ & $55(26-63)^{*}$ \\
Height $(\mathrm{cm})$ & $158.5(150-172)^{*}$ \\
Weight $(\mathrm{kg})$ & $78(70-95)^{*}$ \\
Mallanpati score $(\mathrm{I} / \mathrm{II} / \mathrm{III} / \mathrm{IV})$ & $5 / 5 / 2 / 0 \mu$ \\
Fibreoptic score $(0 / 1 / 2 / 3 / 4)$ & $0 / 0 / 7 / 5 \mu$ \\
Airway sealing pressure $\left(\mathrm{cm} \mathrm{H}_{2} \mathrm{O}\right)$ & $29(22-35)^{*}$ \\
\hline *Data are median (maximum-minimum). $\mu$ Data are number of patients
\end{tabular}

After induction of anaesthesia, ProSeal LMA was inserted in all patients successfully and median insertion time was 18.5 (11-26) seconds. During the surgery, the target cuff pressure in all patients was maintained with cuff manometer. We evaluated LMA placement accuracy with fibreoptic evaluation. Fibreoptic scores were recorded on a scale of 1 to 4 ( 4 = only vocal cords visible; 3 = vocal cords plus posterior epiglottis visible; $2=$ vocal cords plus anterior epiglottis visible; 1 = vocal cords not seen); a score of 1 was considered the worst and a score of 4 was considered the best (3). All patient's fibreoptic scores were equal to or higher than three. ProSeal LMA was not displaced in any patient during the surgery. Also, adequate $\left(>20 \mathrm{~cm} \mathrm{H}_{2} \mathrm{O}\right)$ seal pressure for all patients was provided. In the presence of common adverse effects such as blood staining of the device, sore throat, hoarseness, aphasia, nausea, vomiting and agitation after extubation, the patients were monitored for at least 30 minutes after surgery in the recovery room. None of the patients had dysphagia, dysphonia, sore throat, hoarseness, nausea or vomiting. Blood staining of the LMA was seen in only one patient.

According to our experience, ProSeal LMA can be used with a cuff pressure of $45 \mathrm{~cm}_{2} \mathrm{O}$. This usage may reduce postoperative complications such as blood staining of the device, sore throat and hoarseness. Also, a lower cuff pressure has no negative effects on LMA placement success and airway security.

Keywords: Cuff pressure, postoperative complications, ProSeal laryngeal mask airway

A Ali $^{1}$, N Turgut ${ }^{2}$, IO Akinci ${ }^{1}$

From: 'IU Istanbul Medical Faculty, Department of Anaesthesiology, Istanbul, Turkey and ${ }^{2} S B$ Okymeydani Teaching and Research Hospital, Department of Anaesthesiology, Istanbul, Turkey.

Correspondence: Dr A Ali, İ̈̈ Istanbul Tip Fakültesi Anesteziyoloji ABD Fatih, Istanbul, Türkiye. Fax: +902-12221777; e-mail:a_achmet@hotmail.com

\section{REFERENCES}

1. Brimacombe J, Keller C, Brimacombe L. A comparison of the laryngeal mask airway ProSeal and the laryngeal tube airway in paralyzed anesthetized adult patients undergoing pressure-controlled ventilation. Anesth Anesth Analg 2002; 95: 770-6.

2. Brimacombe J, Holyoake L, Kellar C, Brimacombe N, Scully M, Barry $\mathrm{J}$ et al Pharyngolaryngeal, neck, and jaw discomfort after anesthesia with the face mask and laryngeal mask airway at high and low cuff volumes in males and females. Anesthesiology 2000; 93: 26-31.

3. Keller C, Brimacombe J, Puehringer F. A fibreoptic scoring system to assess the position of laryngeal mask airway devices: interobserver variability and a comparison between the standard, flexible and intubating laryngeal mask airways. Anasthesiol Intensivmed Notfallmed Schmerzther 2000; 35: 692-4. 